\title{
Características fisicoquímicas, sensoriales y microbiológicas de queso crema elaborado con adición de bacterias ácido lácticas como cultivo iniciador
}

\author{
Physicochemical, sensory, and microbiological characteristics of 'queso crema' cheese made \\ with lactic acid bacteria as a starter culture
}

\author{
Elia Morales-Nolasco, Lourdes Adriano-Anaya, Didiana Gálvez-López, Raymundo-Rosas-Quijano, Alfredo Vázquez- \\ Ovando* \\ Instituto de Biociencias, Universidad Autónoma de Chiapas. Boulevard Príncipe Akishino sin número, Colonia Solidaridad \\ 2000. CP. 30798 Tapachula, Chiapas, México.
}

\section{RESUMEN}

El objetivo del presente trabajo fue aislar bacterias ácido lácticas de leche y queso crema del estado de Chiapas, México y evaluar su efecto como cultivo iniciador en las características fisicoquímicas (color, firmeza, consistencia, humedad, acidez titulable, proteína, grasa y cenizas), sensoriales (sabor, aroma, textura, cremosidad y acidez) y microbiológicas (coliformes totales, mohos y levaduras) del mismo queso elaborado a partir de leche pasteurizada. Mediante resiembra consecutiva en placas con agar MRS, se aislaron 101 cepas de diferentes morfologías a partir de muestras de leche y queso crema elaborado con leche no pasteurizada, de las cuales 26 fueron presuntivamente ácido lácticas. Por su capacidad acidificante (descenso del pH) se seleccionaron siete cepas, con las cuales se formularon tres tratamientos (combinaciones de tres cepas, denominados T2-T4). El tratamiento que, después del queso control (T1) sensorialmente fue el más aceptado por los jueces, se reformuló en tres nuevas combinaciones de dos cepas (T5-T7). De estos tratamientos, el T5 (cepas E16 y E23) fue similar en color, aroma, sabor, textura y cremosidad al control (queso elaborado con leche sin pasteurizar). A pesar de que fueron diferentes en cuanto a la acidez, los jueces no lograron diferenciar (prueba cuantitativa) el queso T5 del control.

Palabras clave: índice $\mathrm{R}$, leche no pasteurizada, microorganismos autóctonos, prueba de preferencia.

\section{ABSTRACT}

The aim of this work was to isolate lactic acid bacteria from milk and 'queso crema' cheese and evaluate their effect as starter on physicochemical (color, firmness, consistency, moisture, titratable acidity, protein, fat, and ash), sensory (flavor, aroma, texture, creaminess and sourness), and microbiological (total coliforms, molds and yeasts) characteristics of the same cheese made using pasteurized milk. By consecutive plating on MRS agar, 101 strains of different morphologies were isolated from samples of milk and cheese made with unpasteurized milk, of which 26 were presumptively lactic acid. Due to its acidifying capacity (measured as a decreased in $\mathrm{pH}$ ), seven strains were selected, with which three treatments were formulated (combinations of three strains, called T2-T4). The treatment that, after the control cheese ( $\mathrm{T} 1$ ) was the most accepted by the judge's panel, was reformulated in three new combinations of two strains each (T5-T7). Of these treatments, T5 (containing strains E16 and E23) was similar in color, aroma, flavor, texture and creaminess to the control (cheese made with unpasteurized milk). Although the T5 cheese was different to control in acidity, the judges could not differentiate (quantitative test) between both samples.

Keywords: R index, unpasteurized milk, autochthonous microorganisms, preference test.

\section{INTRODUCCIÓN}

La producción de quesos artesanales es una importante actividad en las regiones de México donde la producción de leche es abundante. Tal actividad ocupa el tercer lugar de productividad dentro de la industria alimenticia y se reporta que para este fin se utiliza el $25 \%$ del total de leche producida en el país (González-Córdova et al., 2016). Actualmente se conocen unos 40 quesos genuinos mexicanos, entre los que destacan los quesos Cotija, Oaxaca, Panela, Chihuahua, de Poro y Queso Crema de Chiapas, entre otros (LozanoMoreno y Villegas-De Gante, 2016). En el estado de Chiapas al sur de México, el queso crema artesanal se elabora en varias regiones socioeconómicas (Istmo-Costa, Norte, Centro, Selva Lacandona, Frailesca). Es un queso muy difundido, con un estatus particular dentro de la industria quesera regional (Granados-Rivera et al., 2018). Este tipo de queso se obtiene a través de la coagulación ácido-enzimática prolongada de leche cruda de vaca y tiene características sensoriales únicas debido al efecto de la microbiota autóctona que se desarrolla en la cuajada. Es un queso de sabor ácido, de pasta fresca, suave y prensada (González-Córdova et al., 2016).

Sin embargo, el uso de leche sin pasteurizar en la preparación de queso crema constituye un riesgo latente para la salud de los consumidores debido a la presencia potencial de microorganismos patógenos como Brucella spp., Mycobacterium tuberculosis, Escherichia coli, Staphylococcus aureus, Listeria monocytogenes (Guzman-Hernandez et al., 2016). Por ello la normativa nacional (NOM-243-SSA1-2010) exige que la leche utilizada en la elaboración de quesos sea 
pasteurizada. Ramos-Izquierdo et al. (2009), demostraron que la pasteurización de la leche reduce a niveles inocuos la carga de posibles patógenos en la leche, pero este proceso también disminuye o elimina la presencia de microorganismos que participan en la generación de las características sensoriales y texturales de los quesos, lo cual perjudica en la comercialización del producto final, ya que los consumidores aprecian los quesos artesanales por sus características singulares de sabor y aroma, que son generalmente atribuidas a la actividad metabólica de la microbiota autóctona presente en la leche cruda (Fortin et al., 2011; Gomes et al., 2011).

Es por ello que, para que se pueda fabricar el queso con leche pasteurizada, es necesario agregar microorganismos acidificantes a la leche (Ramírez-Ramírez et al., 2011). Torres-Llanez et al. (2006) señalan que los microorganismos a utilizar deben ser parte de la biota responsable de proveer características típicas de los quesos que se requieren fabricar (autóctonas), siendo las bacterias ácido lácticas (BAL) uno de los grupos de microorganismos que, por lo general, son los responsables de dicho proceso. Así, muchas de las BAL son utilizadas para elaborar cultivos iniciadores debido a que ayudan en el proceso de acidificación, producen los metabolitos deseables, son seguras (GRAS) para el consumo humano $y$, además participan en la generación de moléculas como péptidos, aminoácidos, ácidos grasos de cadena corta y otros que determinan las cualidades del queso deseado (Møller et al., 2013; De Almeida et al., 2015; Picon et al., 2016).

Las BAL autóctonas han sido empleadas como cultivo iniciador en otros quesos artesanales y se ha demostrado que pueden restablecer las características del queso original elaborado con leche sin pasteurizar (Golić et al., 2013; TerzićVidojević et al., 2015). Por lo anterior, el objetivo de este trabajo fue aislar bacterias ácido lácticas de leche y queso crema elaborado en Pijijiapan al sur de México y evaluar su efecto como cultivo iniciador en las características fisicoquímicas, microbiológicas y sensoriales del mismo queso elaborado a partir de leche pasteurizada.

\section{MATERIALES Y MÉTODOS Obtención de muestras}

Como materia prima para el aislamiento de bacterias ácido lácticas se colectaron en total 27 muestras de diferentes tipos y procedencias (3 sitios, 3 tipos de muestra y 3 réplicas). De tres queserías (sitios) del municipio de Pijijiapan, Chiapas, México: La Esperanza, Alonso Jr y Pichichi se obtuvieron tres productos (tipo de muestra) de cada uno de los tipos: 1) leche recién llegada a la quesería, 2) queso recién elaborado (menos de 5 horas de elaboración) y queso en punto de venta (más de 12 horas de elaborado). Para las muestras de queso se recolectaron quesos completos de $500 \mathrm{~g}$ en bolsas herméticas esterilizadas $y$, para las muestras de leche $1 \mathrm{~L}$ en recipientes de plástico esterilizados, tomados directamente de los contenedores al momento de llegar a la quesería. Posteriormente las muestras se trasladaron en recipientes conteniendo hielo al laboratorio para su posterior análisis.
Las muestras fueron procesadas después de 4 horas (tiempo que duró el traslado), el mismo día que fueron muestreadas.

\section{Aislamiento y selección de microorganismos}

A partir de las muestras se prepararon diluciones seriadas hasta $10^{-6}$ usando agua peptonada como diluyente. Posteriormente, se tomaron $100 \mu \mathrm{L}$ de las diluciones $10^{-4}$, $10^{-5}$ y $10^{-6}$ para inocularlos por extensión usando una varilla de vidrio en placas de Petri conteniendo agar MRS con $\mathrm{pH}$ de $6.5 \pm 0.2$, para después ser puestas en incubación a $37^{\circ} \mathrm{C}$ en condiciones anaerobias por $24 \mathrm{~h}$ (Vázquez-Velázquez et al., 2018). Con las colonias crecidas, se inició el proceso de aislamiento, tomando con un asa las colonias que fueran morfológicamente diferentes en los bordes (circulares o irregulares, ondulados o lisos), la superficie (convexas o planas) y el color (blancas, amarillentas rojizas, opacas, cremosas y brillantes). Para las resiembras consecutivas se empleó agar MRS y se colocaron en condiciones de anaerobiosis durante 24-48 h hasta observar una sola morfología por placa (Vázquez-Velázquez et al., 2018). Posteriormente, a cada una de las cepas se le realizó la prueba de catalasa. A las cepas que resultaron ser catalasa negativas, se les hizo frotis, fijándolas con calor y se tiñeron por el método de Gram para verificar con ayuda de un microscopio óptico Axiolab ${ }^{\circ}$ con analizador de imágenes la morfología microscópica y la coloración, seleccionando las que resultaron Gram positivas y presentaron forma de bacilos o cocos (Vázquez-Velázquez et al., 2018).

\section{Evaluación de la capacidad acidificadora de las cepas seleccionadas}

A las presuntas BAL seleccionadas se les evaluó la capacidad de disminución de $\mathrm{pH}$ de leche entera pasteurizada a temperatura ambiente. Primeramente, las cepas fueron crecidas en caldo MRS con agitación ( $250 \mathrm{rpm}$ ) a temperatura ambiente $\left(30 \pm 2{ }^{\circ} \mathrm{C}\right)$ durante 24 - $48 \mathrm{~h}$, hasta lograr la concentración de $1 \times 10^{8} \mathrm{UFC} / \mathrm{mL}$ (DO a $600 \mathrm{~nm}=1.8$ ). Posteriormente, $500 \mu \mathrm{L}$ de caldo de una de las cepas fueron inoculados en un matraz conteniendo $50 \mathrm{~mL}$ de leche, los cuales fueron colocados en agitador orbital a $125 \mathrm{rpm}$ a temperatura ambiente, realizando mediciones del $\mathrm{pH}$ (pHmetro Starter 2100 OHAUS $\left.^{\circledR}\right)$ a las muestras a las $0,1,2,3,4,5,6,12,24,48$ y $72 \mathrm{~h}$ posteriores a la inoculación (Vázquez-Velázquez et al., 2018).

\section{Formulación de cultivos iniciadores}

Para la selección de las BAL que conformaron los cultivos iniciadores se tomó en cuenta el potencial de acidificación, la formación de grumos en la leche contenida en los matraces y la generación de olor característico a leche fermentada. En la Tabla 1 se muestran las combinaciones que se hicieron a partir de las siete cepas seleccionadas, con estas se procedió a elaborar los quesos de la denominada Etapa 1 (T2-T4, Tabla 1). Posterior a la prueba de degustación de estos quesos se encontró que el queso control elaborado con leche cruda y sin cultivos iniciadores (T1) fue de mayor agrado. Debido a este resultado, se tomaron las BAL (E16, E23 y E41) del tratamiento que mostró el segundo lugar en la prueba 
Tabla 1. Combinaciones de bacterias ácido lácticas empleadas como iniciadores en la elaboración de queso crema de Pijijiapan, Chiapas, México. Table 1. Mixtures of lactic acid bacteria used as starters in the preparation of 'queso crema' cheese from Pijijiapan, Chiapas, Mexico.

\begin{tabular}{lcc}
\hline \multirow{2}{*}{ Tratamientos } & \multicolumn{2}{c}{ Bacterias ácido lácticas empleadas } \\
\cline { 2 - 3 } T1 (control) & -- & Etapa $\mathbf{2}$ \\
\hline T2 & E16, E23 y E41 & - \\
T3 & E11, E12 y P35 & NA \\
T4 & A47, E23 y E41 & NA \\
T5 & NA & NA \\
T6 & NA & E16 y E23 \\
T7 & NA & E16 y E41 \\
\hline
\end{tabular}

La letra que acompaña al número en el código de la cepa indica su procedencia (quesería). $\mathrm{E}=\mathrm{La}$ Esperanza, $\mathrm{A}=$ Alonso Jr y $\mathrm{P}=$ Pichichi. $\mathrm{NA}=$ No Aplica

de nivel de agrado (T2) y fueron combinadas en pares para dar lugar a tres nuevos tratamientos (T5-T7) empleadas en una segunda Etapa (denominada Etapa 2), tal como reporta Cobo-Monterroza et al. (2019).

\section{Preparación del cultivo iniciador y elaboración de queso}

Para preparar los cultivos iniciadores, cada una de las cepas fue crecida en $2 \mathrm{~mL}$ de caldo MRS durante $24 \mathrm{~h}$ a temperatura ambiente $\left(30 \pm 2{ }^{\circ} \mathrm{C}\right)$ hasta alcanzar una concentración de $1 \times 10^{8} \mathrm{UFC} / \mathrm{mL}$, la cual fue verificada mediante lectura de la densidad óptica (1.8) a 600 nm. Posteriormente, se tomaron $500 \mu \mathrm{L}$ de caldo con células de cada cepa y se combinaron según el tratamiento (Tabla 1) en $100 \mathrm{~mL}$ de caldo MRS fresco, etiquetándolas debidamente para después transportarlas en crecimiento ( $24 \mathrm{~h}$ a temperatura ambiente) al lugar donde se elaboraron los quesos (Cobo-Monterroza et al., 2019).

El proceso para la elaboración del queso crema se llevó a cabo de manera artesanal y siguiendo el procedimiento tradicional de la quesería La Esperanza en la colonia Salto de Agua, municipio de Pijijiapan, Chiapas, México. Primeramente, se pasteurizaron $12 \mathrm{~L}$ de leche bronca (por tratamiento), calentando a $63^{\circ} \mathrm{C}$ durante $30 \mathrm{~min}$, transcurrido el tiempo se enfrió en baño de hielo, hasta $35^{\circ} \mathrm{C} \pm 2{ }^{\circ} \mathrm{C}$ y se verificó la ausencia de la enzima fosfatasa mediante la incubación con fenil monofosfato (método 978.14; AOAC, 2010). Posteriormente, se añadieron $250 \mathrm{~g}$ de leche en polvo y se homogenizó la mezcla. Inmediatamente se agregó el cultivo iniciador $(0.5 \%$ v/v) dejándolo reposar por 30 min para garantizar la acción inicial de las BAL's. Después se prosiguió a añadir el cuajo en proporción 1:10 000 v/v y con agitación constante para homogenizar la mezcla. Finalmente, se dejó reposar por $8 \mathrm{~h}$. Transcurrido el tiempo se cortó la cuajada dejándola reposar por $16 \mathrm{~h}$ más. Se colocó la cuajada en costales para escurrirlas por $2 \mathrm{~h}$ para obtener una consistencia semidura, una vez que esto se logró, se continuó con el salado de forma manual (100 g/L aprox.) y se escurrió nuevamente la cuajada por 3 h. Llegado el tiempo se prosiguió al moldeado de los quesos para el subsiguiente prensado durante $18 \mathrm{~h}$ y finalmente empaquetarlos. Terminado el proceso, los quesos fueron empleados para realizarles pruebas sensoriales (Etapas 1 y 2), fisicoquímicas y microbiológicas (Etapa 2).

\section{Evaluación sensorial}

Para evaluar el efecto de los cultivos iniciadores en las propiedades sensoriales del queso crema, se realizaron pruebas de evaluación sensorial para cada una de las Etapas. En la Etapa 1, se realizó una prueba de aceptación con un panel de 39 jueces no entrenados (consumidores), estudiantes universitarios (19 hombres y 20 mujeres) con edades entre 18-25 años y consumidores habituales de queso crema. A estos panelistas, se les dio a probar raciones de $1 \mathrm{~cm}^{3}$ de los diferentes quesos elaborados con leche pasteurizada y con los cultivos iniciadores (T2-T4) más el queso control (T1), cada uno codificado con tres dígitos diferentes. Después se les pidió que ordenaran de acuerdo a su nivel de agrado cada una de las muestras en orden creciente de nivel de agrado, donde $1=$ menor agrado y $4=$ mayor agrado. De esta Etapa se obtuvo el queso con mayor nivel de agrado. Para la segunda Etapa (T5-T7), se repitió la prueba de nivel de agrado, esta vez con 31 panelistas no entrenados (15 hombres y 16 mujeres) con edades de entre 18 y 50 años de edad, con experiencia en la degustación de quesos artesanales. Se procedió del mismo modo que en la Etapa 1 para obtener el queso con el mayor nivel de agrado, mediante la prueba de preferencia (prueba afectiva).

Para mostrar la preferencia de alguna muestra sobre las demás se calcularon los índice $\mathrm{R}$ hedónicos (Wichchukit y O'Mahony, 2015). El índice R es una medida de sensibilidad que se refleja como un valor estimado de la probabilidad de que un juez pueda distinguir una señal sensorial. Este índice estima el porcentaje de cuantas comparaciones pareadas, entre dos muestras evaluadas, indicaría correctamente el juez o grupo de jueces con respecto a la señal buscada, por lo que se considera como una estimación de la probabilidad con la que un juez o grupo de jueces detecte la diferencia entre dos muestras de acuerdo con una característica específica y debido a que la probabilidad de acierto por azar es 1/2, un índice de 50 \% indicaría que no hay diferencia. Mientras más se acerca este último a $100 \%$ será mayor la diferencia de los estímulos (Chaparro-Hernández et al., 2013). Este mismo criterio puede ser empleado con pruebas de ordenamiento del nivel de agrado y las respuestas indican el nivel de preferencia de una muestra sobre otra (Wichchukit y O'Mahony, 2015).

Finalmente, el queso con el mayor nivel de agrado de la Etapa 2, fue "confrontado" con el queso elaborado de manera tradicional (tratamiento T1) mediante una prueba descriptiva cuantitativa. Para ello, se proporcionó a trece jueces expertos (productores de queso con más de diez años de experiencia en la elaboración de queso crema) dos muestras, una del queso seleccionado y la otra del queso control (ambas codificadas con tres dígitos). Después, se les pidió que le otorgaran a cada muestra de manera independiente 
una puntuación (considerando $1=$ menor intensidad y $7=$ mayor intensidad del atributo) para cada uno de los siguientes atributos: aroma, sabor, textura, cremosidad y acidez. Los resultados obtenidos se calificaron mediante una prueba de puntos (Esmerino et al., 2013).

\section{Análisis microbiológico de los quesos}

Al queso seleccionado (T5) y al control (T1) se les determinó mediante conteo en placa la carga de hongos y levaduras (NOM-111-SSA1-1994) así como de coliformes totales (NOM-113-SSA1-1994).

\section{Características fisicoquímicas de los quesos}

A los quesos elaborados (T5 y control) se les determinó el color (colorímetro MiniScan EZ), firmeza y consistencia con el analizador de textura TA1, contenido de grasa total por el método 933.05, nitrógeno por el método 920.123, humedad (método 926.08), cenizas (método 935.42) y acidez titulable (920.124) siguiendo los métodos descritos por la AOAC (2010). El contenido de proteína fue calculado multiplicando por 6.38 el contenido de nitrógeno.

\section{Análisis de datos}

Los datos obtenidos en la prueba sensorial de aceptación fueron analizados mediante el cálculo del índice $\mathrm{R}$; el cual fue comparado con los valores críticos obtenidos de Bi y O'Mahony (2007) para determinar la significancia estadística. Los datos de la prueba sensorial cuantitativa fueron sometidos a un análisis de varianza no paramétrico (prueba de Kruskal Wallis, $\mathrm{a}=0.05$ ) y posterior comparación de rangos. Los datos de las pruebas instrumentales y de composición se compararon mediante una prueba $t$ de Student. Todos los análisis se realizaron mediante el empleo del software estadístico Infostat v.2016.

\section{RESULTADOS Y DISCUSIÓN}

\section{Aislamiento y purificación de microorganismos}

De todas las muestras analizadas se aislaron 101 cepas en agar MRS, las cuales presentaron características morfológicas macroscópicas de bacterias ácido lácticas que incluyen colonias pequeñas y medianas, de colores blanco, beige, de aspecto lechoso y con borde entero (Kandler y Weiss, 1992). Las cepas fueron codificadas con una letra que denota la quesería de procedencia y un número secuencial (Tabla 2).

Después de verificar la ausencia de actividad de la catalasa, la colección original de 101 cepas se redujo a 45 cepas. Después de revisar la morfología microscópica (bacterias y/o cocos) y la coloración de la tinción (Gram +), el número de BAL disminuyó a 26 morfologías diferentes (Tabla 2). De este total, ocho cepas fueron aisladas de la quesería La Esperanza (cuatro de queso y cuatro de leche), 14 de la quesería Pichichi (todas de leche) y cuatro de la quesería Alonso Jr (tres de queso y una de leche) (Tabla 3). El mayor número de cepas (19) fueron aisladas de muestras de leche y ninguna cepa fue asiladas de queso recién elaborado. El número total de cepas aisladas en el presente estudio resulta inferior al reportado por Cobo-Monterroza et al. (2019) para un producto similar (queso crema) de la región de Ocosingo, Chiapas, México. Esta diferencia puede ser debida a la naturaleza de las muestras empleadas como fuente de las cepas, pues en el estudio citado también se incluyeron muestras de suero. Sin embargo, en ese mismo estudio se reportó que las presuntas BAL son principalmente aisladas de leche y queso, razón por la cual las muestras de suero no se incluyeron en el presente estudio. Las 26 BAL encontradas representan el $25.74 \%$ del total de cepas aisladas de queso y leche. Este valor es menor al reportado por otros autores; Ortiz-Balderas (2006) encontró $84.34 \%$ de BAL de un total de 332 cepas aisladas de diferentes tipos de quesos y leche; este gran número puede deberse a la cantidad y a los 12 tipos de muestras utilizadas, entre ellas quesos frescos, quesos madurados y leche; así mismo González et al. (2015) reportaron $76.39 \%$ de bacterias ácido lácticas aisladas en tres diferentes medios de cultivo.

\section{Evaluación de la capacidad acidificadora de las cepas aisladas y formulación de los cultivos iniciadores}

Las 26 cepas seleccionadas por sus características morfológicas y bioquímicas fueron sometidas a evaluación de capacidad acidificadora en leche pasteurizada. En la Figura 1 se muestran las cinéticas del $\mathrm{pH}$ en leche inoculada con las BAL aisladas de queso (1A) y de leche (1B). Durante las prime-

Tabla 2. Clasificación de las cepas de bacterias ácido lácticas aisladas de distintas muestras, en función de pruebas bioquímicas. Table 2. Classification of lactic acid bacteria strains isolated from different samples, based on biochemical tests.

\begin{tabular}{|c|c|c|c|c|}
\hline Prueba & & Queso recién elaborado & Queso en venta & Leche \\
\hline \multirow[t]{2}{*}{ Catalasa } & + & $\begin{array}{c}\text { E2-8, P19-22, A29-30, A32-33, } \\
\text { P34-35 P38 } \\
(18)\end{array}$ & $\begin{array}{c}\text { E13-15, E17, A23-24, A26-28, P36-37, E39- } \\
\text { 40, E42, A43, A45, A48-49 } \\
(18)\end{array}$ & $\begin{array}{c}\mathrm{A} 1-4, \mathrm{~A} 9-10, \mathrm{P} 11, \mathrm{P} 17, \mathrm{E} 21, \mathrm{E} 24, \mathrm{P} 32, \mathrm{P} 34, \mathrm{E} 39- \\
\text { 40, A41, A46-47, A49-50, A52 } \\
(20)\end{array}$ \\
\hline & - & $\begin{array}{l}\text { E1, E9 y } A 31 \\
\text { (3) }\end{array}$ & $\begin{array}{c}\text { E10-12, E16, E18, A25, E41, A44, A46-47 } \\
\text { (10) }\end{array}$ & $\begin{array}{c}\text { A5-8, P12-16, P18, E19-20, E22-23, E25-26, P27- } \\
\text { 31, P33, P35-38, A42-45, L48, A51 (32) }\end{array}$ \\
\hline \multirow{2}{*}{ Tinción Gram } & + & (0) & $\begin{array}{c}E 11, E 12, E 16, E 41, A 44, A 46, A 47 \\
\text { (7) }\end{array}$ & $\begin{array}{c}\text { A6, P13-16, E19-20, E22-23, P27-31, P33, P35-38 } \\
\text { (19) }\end{array}$ \\
\hline & - & $\begin{array}{c}\mathrm{E1}, \mathrm{E9}, \mathrm{A} 31 \\
(3)\end{array}$ & $\begin{array}{l}\mathrm{E} 10, \mathrm{E} 18 \text { y } \mathrm{A} 25 \\
\text { (3) }\end{array}$ & $\begin{array}{c}\text { A5, A7-8, P12, P18, E25-26, A42-45, A48, A51 } \\
\text { (12) }\end{array}$ \\
\hline
\end{tabular}

La letra denota la quesería de origen de la muestra, $A=$ Alonso Jr, $E=$ La Esperanza y $P=$ Pichichi.

El número total de cepas se muestra entre paréntesis. 
Tabla 3. Cantidad final de cepas de bacterias ácido lácticas (BAL) aisladas en función del tipo y origen de la muestra.

Table 3. Number of strains of lactic acid bacteria (LAB) isolated depending on the type and origin of the sample.

\begin{tabular}{lccc}
\hline Quesería & Muestra & $\begin{array}{c}\text { Número total } \\
\text { de colonias }\end{array}$ & Número final de BAL \\
\hline La Esperanza & QRE & 9 & 0 \\
& QV & 13 & 4 \\
\hline Pichichi & L & 10 & 4 \\
\hline & QRE & 7 & 0 \\
\hline Alonso Jr. & QV & 2 & 0 \\
& L & 20 & 14 \\
& QRE & 5 & 0 \\
\hline & QV & 13 & 3 \\
\hline
\end{tabular}

$\mathrm{QV}=\mathrm{Queso}$ en venta, $\mathrm{QRE}=\mathrm{Queso}$ recién elaborado y $\mathrm{L}=$ Leche

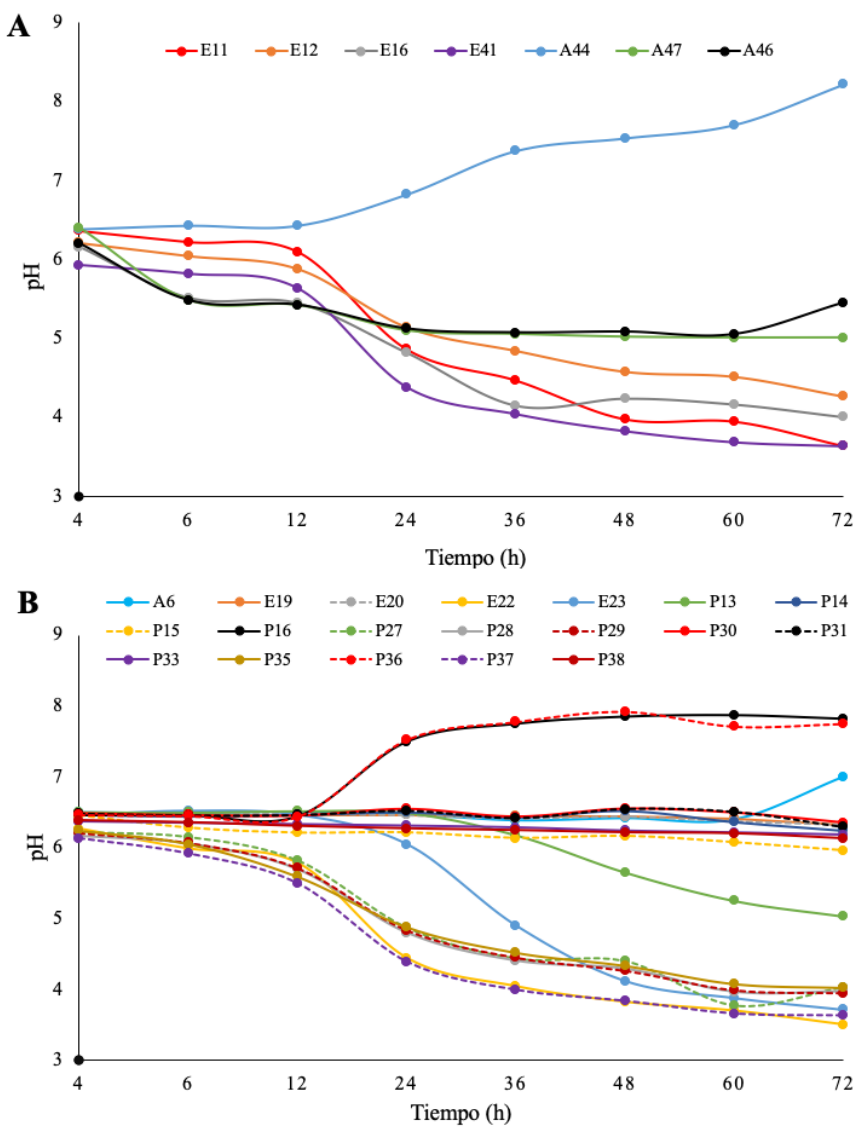

Figura 1. Cinéticas de $\mathrm{pH}$ de leche inoculada con cepas aisladas de muestras de queso crema $(A)$ y de leche $(B)$ empleada en la elaboración de queso crema.

Figure 1. $\mathrm{pH}$ kinetics of milk inoculated with strains isolated from samples of cream cheese (A) and milk (B) used in the preparation of 'queso crema' cheese. ras cuatro horas no se observaron descensos importantes en el $\mathrm{pH}$ (datos no mostrados), lo cual podría estar relacionado con las fases de adaptación al medio y de crecimiento exponencial de las BAL. Posterior a la $4^{\text {a }}$ hora se inició para algunas cepas la producción importante de compuestos que modifican el pH de la leche. La disminución del pH es consecuencia de la fermentación de lactosa para producir principalmente ácido láctico (Pszczola, 2007). Con excepción de la cepa A44, las cepas aisladas de queso, tuvieron el comportamiento típico de las BAL (Figura 1A); sin embargo, para las cepas aisladas de leche se observaron tres tipos de comportamiento, un grupo de bacterias que acidificaron la leche después de $72 \mathrm{~h}$, otro grupo que no modificaron sustancialmente el $\mathrm{pH}$ inicial y un tercer grupo de dos cepas que al igual que la cepa A44 alcalinizaron la leche (Figura 1B). Este último comportamiento totalmente inusual para presuntas BAL podría ser un indicio de la presencia de contaminación en el inóculo (Alfonso y Cabeza-Herrera, 2006), pues se ha reportado este comportamiento en fermentaciones promovidas por levaduras; o más aún (puesto que se repitió el procedimiento) podría tratarse de bacterias del grupo del ácido láctico con comportamiento heterofermentativo y producción de amonio, citrulina u otro compuesto que alcaliniza el medio y que se ha reportado en otras fermentaciones ácido-lácticas (Mira-de Orduña et al., 2001). Una última opción podría ser que tales cepas no corresponden al grupo de las bacterias ácido lácticas.

Otra característica de las BAL asociada con la disminución del $\mathrm{pH}$, es la producción de otros metabolitos (peróxido de hidrógeno, bacteriocinas, péptidos, etc.) que tienen un importante efecto sobre otros microorganismos considerados patógenos o no deseados. Además de incidir en la vida de anaquel del producto, la presencia del ácido láctico desnaturaliza las proteínas dando lugar a la sinéresis y la formación de sabor y aroma (Walstra et al., 2001), pues su presencia se asocia con un sabor ácido suave y agradable, que no domina sobre otros compuestos aromáticos y realza el sabor (Pszczola, 2007). Se encontraron 14 cepas con potencial para acidificar la leche, 6 cepas aisladas de queso en venta (E11, E12, E16, E41, A46 y A47) y 8 aisladas de leche (P15, E22, E23, P27, P28, P29, P35 y P37). De todas estas, además de las características antes mencionadas (sección de materiales y métodos) para su selección se tomó en cuenta dos características relevantes, que son la adaptación y crecimiento rápido (datos no mostrados) siendo E11, E12, E16, E41, A47, E23 y P35 las que cumplieron con los requisitos. En la Tabla 1 se muestran las combinaciones de las BAL empleadas como iniciadores en la elaboración del queso crema.

\section{Evaluación sensorial de quesos crema elaborados con cultivos iniciadores}

Para la primera etapa de la prueba de aceptación se incluyó un queso elaborado con leche bronca de manera tradicional (Control, T1) frente a los quesos elaborados con leche pasteurizada y adicionados con iniciadores $(B A L)$ para comparar el grado de aceptación de estos últimos. El queso control (T1) resultó la muestra mejor evaluada ya que obtuvo un valor promedio (contrastado con los demás tratamientos) 
de $66.6 \%$ para el índice $\mathrm{R}$, siendo el valor más alto y significativamente diferente de T3 y de T4 (Tabla 4). Este resultado es un comportamiento usual cuando se trata de una muestra consumida regularmente, pues los consumidores tienden a preferir lo tradicional cuando detectan ligeras diferencias (Guerrero et al., 2009). Lo anterior demuestra que la adición de las BAL a la leche pasteurizada en las muestras T2-T4 no logró igualar las características del queso control y consecuentemente la preferencia de los consumidores. Por esta razón se optó por reformular el T2, que después del control fue el que mostró mayor nivel de agrado con valor promedio del índice R de 53.3 \% y que en los contrastes individuales fue significativamente diferente del T4 (Tabla 4). Las nuevas combinaciones de las cepas E16, E23 y E41, que conformaron originalmente el tratamiento 2 dieron origen a los tratamientos T5-T7 (Tabla1).

Tabla 4. Valor del índice R para cada comparación de tratamientos evaluados en la elaboración de queso crema.

Table 4. $R$ index value for each treatment comparison evaluated in the production of 'queso crema' cheese.

\begin{tabular}{|c|c|c|c|}
\hline \multicolumn{4}{|c|}{ Índice R (\%) } \\
\hline \multicolumn{2}{|c|}{ Primera Etapa ${ }^{a}$} & \multicolumn{2}{|c|}{ Segunda Etapab } \\
\hline T1 sobre T2 & 57.6 & \multirow{2}{*}{ T5 sobre T6 } & \multirow{2}{*}{$75.9^{* *}$} \\
\hline $\mathrm{T} 2$ sobre $\mathrm{T} 1$ & 42.4 & & \\
\hline T1 sobre T3 & $66.3^{*}$ & \multirow{2}{*}{ T6 sobre T5 } & \multirow{2}{*}{24.1} \\
\hline T3 sobre T1 & 33.7 & & \\
\hline T1 sobre T4 & $76.1^{*}$ & \multirow{2}{*}{ T5 sobre T7 } & \multirow{2}{*}{$78.4^{* *}$} \\
\hline T4 sobre T1 & 23.9 & & \\
\hline T2 sobre T3 & 49.0 & \multirow{2}{*}{ T7 sobre T5 } & \multirow{2}{*}{21.6} \\
\hline T3 sobre T2 & 51.0 & & \\
\hline $\mathrm{T} 2$ sobre $\mathrm{T} 4$ & $68.6^{*}$ & \multirow{2}{*}{ T6 sobre T7 } & \multirow{2}{*}{56.5} \\
\hline T4 sobre T2 & 31.4 & & \\
\hline T3 sobre T4 & 56.0 & \multirow{2}{*}{ T7 sobre T6 } & \multirow{2}{*}{43.5} \\
\hline T4 sobre T3 & 44.0 & & \\
\hline
\end{tabular}

aValores con * indican diferencia significativa, $n=39, a=0.05$ y dos colas. ${ }^{b}$ Valores con ${ }^{* *}$ indican diferencia significativa, $n=31, a=0.05$ y dos colas. Ambos determinados según los valores críticos de Bi y O'Mahony (2007).

En la segunda Etapa de la prueba de aceptación fue el tratamiento 5 el que obtuvo el mayor índice $\mathrm{R}$ con un valor promedio de $77.2 \%$ sobre los demás tratamientos y diferente en los contrastes individuales de los otros dos tratamientos (Tabla 4), siendo éste el queso que se tomó en cuenta para las posteriores pruebas. Cobo-Monterroza et al. (2019) realizaron un procedimiento de reformulación de los cultivos iniciadores en un estudio con un queso similar y mencionan que uno de los cultivos reformulados logró generar las características típicas del queso convencional al elaborar queso con leche pasteurizada.

Derivado del análisis no paramétrico (prueba de Kruskall Wallis) de los datos obtenidos de la prueba cuantitativa, se encontró que no hubo diferencias en las variables evaluadas por los panelistas (Tabla 5). Lo anterior demuestra
Tabla 5. Valores promedio para descriptores sensoriales otorgados por panelistas a muestras de queso crema comparado con datos de queso fresco.

Table 5. Average values for sensory descriptors scored by panelists to samples of 'queso crema' cheese compared with fresh cheese.

\begin{tabular}{lccc}
\hline \multirow{2}{*}{ Variables } & \multicolumn{3}{c}{ Quesos } \\
\cline { 2 - 4 } & Control (T1) & T5 & Queso fresco $^{1}$ \\
\hline Aroma & $4.85 \pm 2.12^{\mathrm{a}}$ & $4.54 \pm 1.98^{\mathrm{a}}$ & 4.50 \\
Sabor & $5.15 \pm 1.14^{\mathrm{a}}$ & $5.15 \pm 1.72^{\mathrm{a}}$ & - \\
\hline Textura & $4.69 \pm 1.49^{\mathrm{a}}$ & $4.31 \pm 1.65^{\mathrm{a}}$ & - \\
Cremosidad & $4.69 \pm 1.49^{\mathrm{a}}$ & $4.85 \pm 1.52^{\mathrm{a}}$ & - \\
Acidez & $4.62 \pm 1.66^{\mathrm{a}}$ & $5.23 \pm 1.30^{\mathrm{a}}$ & 4.30 \\
\hline
\end{tabular}

T1: elaborado con leche sin pasteurizar. T5: elaborado con leche pasteurizada y adicionado con bacterias ácido lácticas como cultivo iniciador. Promedios con letras iguales por variable denotan igualdad estadística ( $p>0.05)$. ${ }^{1}$ Terzić-Vidojević et al. (2015).

que las BAL usadas como cultivo iniciador en T5 producen los metabolitos necesarios para obtener características sensoriales similares al queso crema elaborado de manera convencional, tal como reportan Ramos-Izquierdo et al. (2009) en la elaboración de queso crema tropical utilizando cepas de L. fermentum y L. pentosus. Sameh et al. (2007) también reportaron que las calificaciones sensoriales otorgadas a los quesos elaborados con el cultivo láctico YY47 y adicionado con cepas de L. helveticus, L. paracasei subsp. paracasei, $L$. delbrueckii susp. lactis y Enterococcus faecium eran más altas respecto de su tratamiento Testigo.

\section{Análisis microbiológico}

La caracterización microbiológica de los quesos hace pensar que las condiciones de inocuidad de los lugares donde se elaboraron los quesos son deficientes, pues la cuenta de coliformes totales, mohos y levaduras encontrada en ambos quesos (Tabla 6) resulta superior a los límites sugeridos por la norma mexicana para quesos pasteurizados (NOM-243-SSA1-2010). En los quesos elaborados con leche pasteurizada (T5) la carga está reducida respecto al queso Control.

Las altas cargas de los microorganismos indicadores pueden estar relacionadas con post-procesamiento inapropiado de la cuajada, como son la manipulación tanto de los equipos y utensilios como de la propia cuajada (Genigeorgis

Tabla 6. Cuenta en placa para coliformes totales, mohos y levaduras del queso crema elaborado de manera convencional (Control) y a partir de leche pasteurizada y cultivo iniciador (T5).

Table 6. Plate count for total coliforms, molds and yeasts of 'queso crema' cheese traditionally made (Control) and with pasteurized milk and starter added (T5).

\begin{tabular}{lccc}
\hline \multirow{2}{*}{ Prueba } & \multicolumn{3}{c}{ UFC/g } \\
\cline { 2 - 4 } & Control & T5 & Límite Máximo \\
\hline Coliformes totales & $3.97 \times 10^{4}$ & $1.24 \times 10^{4}$ & $\leq 100$ \\
Mohos y levaduras & $2.19 \times 10^{4}$ & $1 \times 10^{3}$ & 500 \\
\hline
\end{tabular}

Ensayos triplicados empleando las diluciones seriadas de 1:100, 1: 1000, 1: 10000 . 
et al., 1991; Kasrazadeh y Genigeorgis, 1994). Otro factor puede ser las condiciones del local, dado que este no contaba con barreras para evitar la entrada de insectos, roedores y otros animales. Se ha reportado que la presencia de levaduras como contaminantes (lo cual pudo darse) favorece la síntesis de factores de crecimiento como vitaminas y compuestos nitrogenados solubles, los cuales tienden a aumentar la carga de microorganismos no deseables. Lo anterior demuestra que el solo uso del cultivo iniciador no logra reducir las cargas de coliformes, mohos y levaduras que podrían ser perjudiciales para el consumidor y que es necesario acompañar este proceso de la implementación de buenas prácticas de manufactura (BPM) tal como sugiere Rangel-Ortega (2011).

\section{Características fisicoquímicas del queso crema}

En casi todos los parámetros fisicoquímicos evaluados se encontraron diferencias $(p<0.05)$ entre muestras, exceptuando el color y el contenido de cenizas (Tabla 7). La igualdad con respecto al color puede explicarse por el hecho de que ambos quesos fueron elaborados con las mismas cantidades de materia prima (leche, cuajo y sal) proveniente del mismo lote. Los valores obtenidos en cuanto al contenido de cenizas para ambas muestras son altos con respecto a lo reportado por Cobo-Monterroza et al. (2019) pero similares a los que reportan Romero-Castillo et al. (2009), quienes lo atribuyen principalmente al origen y la calidad de la leche aunado al tipo de alimentación del ganado. Las diferencias en los demás parámetros puede ser un indicio del efecto de las BAL adicionadas a la leche durante el procesamiento. Los valores en el contenido de acidez titulable son relativamente bajos si se comparan con los reportados por Rangel-Ortega
(2011), pero son similares a los valores reportados por RamosIzquierdo et al. (2009), además en los quesos del tratamiento T5 fue mayor que en el queso control, debido al metabolismo anaerobio de las BAL adicionadas.

Con respecto a la humedad, las diferencias entre el tratamiento $\mathrm{T} 5 \mathrm{y}$ el control pueden deberse a factores como el tratamiento térmico de la leche que favorece la retención de humedad (Morales-Celaya et al., 2012) o bien a que las BAL adicionadas al T5 sean productoras de exopolisacáridos, los cuales se ha reportado que incrementan la retención de humedad en quesos (Cárdenas et al., 2014). En cuanto al contenido de proteínas, la diferencia encontrada se puede deber parcialmente al proceso de pasteurización, pues se ha reportado que el tratamiento térmico de la leche por encima de los $60^{\circ} \mathrm{C}$ promueve la desnaturalización de las proteínas del suero de la leche, lo que al final da como resultado la transferencia de mayor cantidad de proteínas del suero a la cuajada (Morales-Celaya et al., 2012; Sánchez-Macías et al., 2013). Otra posibilidad es que las bacterias "contaminantes" del queso control (T1) expresan gran actividad proteolítica, dando como consecuencia la liberación de péptidos de la cuajada hacia el suero. El queso control presentó menor contenido de grasas con respecto al queso del T5. Este queso también obtuvo mayores valores de firmeza y consistencia, demostrando de esta manera lo que Küçüköner y Haque (2006) explican, a medida que disminuye el contenido de grasa en el queso, se aumenta la firmeza. Esto es apoyado por los resultados reportados por Zheng et al. (2016) quienes además explican que la firmeza se ve afectada por el contenido de grasas y de humedad de los quesos.

Tabla 7. Características fisicoquímicas del queso crema elaborado de manera convencional (Control) y a partir de leche pasteurizada y cultivo iniciador (T5).

Table 7. Physicochemical characteristics of 'queso crema' cheese traditionally made (Control) and with pasteurized milk and starter added (T5).

\begin{tabular}{|c|c|c|c|c|c|}
\hline \multirow[b]{2}{*}{ Parámetros } & \multicolumn{5}{|c|}{ Quesos } \\
\hline & \multicolumn{2}{|c|}{ Control } & \multicolumn{2}{|c|}{ T5 } & \multirow{2}{*}{$\begin{array}{c}\begin{array}{c}\text { Queso crema de } \\
\text { Ocosingo, } \\
\text { Chiapas, México' }\end{array} \\
90.97\end{array}$} \\
\hline \multirow{3}{*}{ Color } & 91.19 & $\pm 0.43^{\mathrm{a}}$ & 91.68 & $\pm 0.79^{\mathrm{a}}$ & \\
\hline & 0.22 & $\pm 0.14^{\mathrm{a}}$ & 0.41 & $\pm 0.20^{\mathrm{a}}$ & -0.15 \\
\hline & 16.37 & $\pm 0.95^{\mathrm{a}}$ & 15.54 & $\pm 0.91^{\mathrm{a}}$ & 18.57 \\
\hline Firmeza (N) & 4.61 & $\pm 0.91^{\mathrm{a}}$ & 1.57 & $\pm 0.29^{\mathrm{b}}$ & 4.68 \\
\hline Consistencia (Nmm) & 50.63 & $\pm 4.82^{\mathrm{a}}$ & 17.57 & $\pm 0.98^{\mathrm{b}}$ & - \\
\hline Humedad (\%) & 47.59 & $\pm 0.04^{\mathrm{a}}$ & 53.23 & $\pm 1.50^{\mathrm{b}}$ & 51.32 \\
\hline $\begin{array}{l}\text { Acidez titulable (\% ácido } \\
\text { láctico) }\end{array}$ & 0.90 & $\pm 0.10^{\mathrm{a}}$ & 1.30 & $\pm 0.10^{\mathrm{b}}$ & - \\
\hline Cenizas (\% b.s.) & 8.27 & $\pm 0.04^{\mathrm{a}}$ & 8.53 & $\pm 0.43^{\mathrm{a}}$ & 3.02 \\
\hline Grasa (\% b.s.) & 11.07 & $\pm 0.76^{\mathrm{a}}$ & 15.76 & $\pm 0.60^{\mathrm{b}}$ & 25.74 \\
\hline Proteína (\% b.s.) & 14.15 & $\pm 1.27^{\mathrm{a}}$ & 19.23 & $\pm 0.55^{\mathrm{b}}$ & 21.26 \\
\hline
\end{tabular}

Control: Queso elaborado con leche sin pasteurizar y sin cultivos lácticos.

T5: Queso elaborado con leche pasteurizada y cultivos lácticos de las cepas E16 y E23.

Valores con letras iguales por variable denotan igualdad estadística ( $p>0.05)$.

${ }^{1}$ Cobo-Monterroza et al. (2019) 


\section{CONCLUSIONES}

A partir de muestras de leche y queso crema de la costa del estado de Chiapas. México fue posible aislar bacterias ácido-lácticas que resultaron útiles en la elaboración de queso a partir de leche pasteurizada. El tratamiento formulado con las cepas E16 y E23 (T5) demostró tener aceptabilidad entre los consumidores, además de que los jueces no encontraron diferencia entre un queso elaborado tradicionalmente con leche cruda y el queso del tratamiento T5 cuando se aplicó una prueba sensorial cuantitativa. El uso de BAL en el proceso de elaboración aumentó el contenido de humedad, ácido láctico, proteínas y grasa en el queso crema. Desafortunadamente, tanto el queso tradicional como el elaborado con BAL presentaron cuentas por arriba de las establecidas en la normativa para coliformes totales así como para mohos y levaduras revelando posibles deficiencias en las buenas prácticas de manufactura (BPM).

\section{AGRADECIMIENTOS}

Los autores agradecen a la quesería "La Esperanza" así como a Fidel Cruz Alfaro, Carlos Cruz Alfaro y Apolinar Trinidad Colmenares por su invaluable apoyo en la elaboración de los quesos.

\section{REFERENCIAS}

Alfonso, E. y Cabeza-Herrera, E. 2006. Bacterias ácido lácticas (BAL): aplicaciones como cultivos estárter para la industria láctea y cárnica. Simposio Regional de Microbiología: Microorganismos Eficientes en el Sector Productivo, At Universidad Libre Seccional Barranquilla-Colombia, doi: 10.13140/2.1.2241.2169.

AOAC. 2010. Official Methods of Analysis. 18 Edition. Association of Official Analytical Chemists. Washington DC, USA.

Bi, J. y O'Mahony, M. 2007. Updated and extended table for testing the significance of the R-index. Journal of Sensory Studies. 22(6): 713-720.

Cárdenas, N., Calzada, J., Peirotén, A., Jiménez, E., Escudero, R., Rodríguez, J.M., Medina, M. y Fernández, L. 2014. Development of a potential probiotic fresh cheese using two Lactobacillus salivarius strains isolated from human milk. BioMed Research International. Article ID 801918.

Chaparro-Hernández, J., Castillejos-Gómez, B.I, CarmonaEscutia, R.P., Escalona-Buendía, H.B. y Pérez-Chabela, M.L. 2013. Evaluación sensorial de salchichas con harina de cáscara de naranja y/o penca de maguey. NACAMEH. 7: 2340.

Cobo-Monterroza, R., Rosas-Quijano, R., Gálvez-López, D. Adriano-Anaya, L., Vázquez-Ovando, A. 2019. Bacterias ácido lácticas nativas como cultivo iniciador para la elaboración de queso crema mexicano. Agronomía Mesoamericana. Aceptado.

De Almeida, J.W.L., da Silva-Ferrari, Í., Souza, J.V., da Silva, C.D.A., da Costa, M.M. y Dias, F.S. 2015. Characterization and evaluation of lactic acid bacteria isolated from goat milk. Food Control. 53: 96-103.

Esmerino, E.A., Cruz, A.G., Pereira, E.P., Rodrigues, J.B., Faria, J.A. y Bolini, H. M. 2013. The influence of sweeteners in probiotic Petit Suisse cheese in concentrations equivalent to that of sucrose. Journal of Dairy Science. 96(9): 5512-5521.
Fortin, M.H., Champagne, C.P., St-Gelais, D., Britten, M., Fustier, P. y Lacroix, M. 2011. Effect of time of inoculation, starter addition, oxygen level and salting on the viability of probiotic cultures during Cheddar cheese production. International Dairy Journal. 21(2): 75-82.

Genigeorgis, C., Carniciu, M., Dutulescu D. y Farver, T.B. 1991. Growth and survival of Listeria monocytogenes in market cheeses stored at 4 to $30{ }^{\circ} \mathrm{C}$. Journal of Food Protection. 54(9): 662-668.

Golić N., Cadež, N., Terzić-Vidojević, A., Suranská, H., Beganović, J., Lozo, J., Kos, B., Sušković, J., Raspor, P. y Topisirović, L. 2013. Evaluation of lactic acid bacteria and yeast diversity in traditional white pickled and fresh soft cheeses from the mountain regions of Serbia and lowland regions of Croatia. International Journal of Food Microbiology. 166(2): 294-300.

Gomes A.A., Braga, S.P., Cruz, A.G., Cadena, R.S., Lollo, P.C., Carvalho, C., Amaya-Farfán, J., Faria, J.A. y Bolini, H.M. 2011. Effect of the inoculation level of Lactobacillus acidophilus in probiotic cheese on the physicochemical features and sensory performance compared with commercial cheeses. Journal of Dairy Science. 94(10): 4777-4786.

González, L., Fernández-Cuadrillero, A., Castro, J.M., Bernardo, A. y Tornadijo, M.E. 2015. Selection of lactic acid bacteria isolated from San Simón da Costa Cheese (PDO) in order to develop an autochthonous starter culture. Advances in Microbiology. 5: 748-749.

González-Córdova, A.F., Yescas, C., Ortiz-Estrada, Á.M., De la RosaAlcaraz, M. A., Hernández-Mendoza, A. y Vallejo-Cordoba, B. 2016. Invited review: Artisanal Mexican cheeses. Journal of Dairy Science. 99(5): 3250-3262.

Granados-Rivera, L.D., Hernández-Mendo, O., BurgueñoFerreira, J.A., González-Muñoz, S.S., Mendoza-Martínez, G.D., Mora-Flores, J.S. y Arriaga-Jordán C.M. 2018. Mexican tropical cream cheese yield using low-fat milk induced by trans-10, cis-12 conjugated linoleic acid: effect of palmitic acid. CyTA-Journal of Food. 16(1): 311-315.

Guerrero, L., Guàrdia, M.A., Xicola, J., Verbeke, W., Vanhonacker, F., Zakowska-Biemans, S., Sajdakowska, M., Sulmont-Rossé, C., Issanchou, S., Contel, M., Scalvedi, M. L., Granli, B.S. y Hersleth, M. 2009. Consumer-driven definition of traditional food products and innovation in traditional foods. A qualitative cross-cultural study. Appetite. 52(2): 345-354.

Guzman-Hernandez, R., Contreras-Rodriguez, A., HernandezVelez, R., Perez-Martinez, I., Lopez-Merino, A., Zaidi, M.B. y Estrada-Garcia, T. 2016. Mexican unpasteurised fresh cheeses are contaminated with Salmonella spp., non-0157 Shiga toxin producing Escherichia coli and potential uropathogenic E. coli strains: A public health risk. International Journal of Food Microbiology. 237: 10-16.

Kandler, O. y Weiss N. 1992. Regular, nonsporing Gram-positive rods. En P. H. A. Sneath, M.S. Mair, M.E. Sharp y J.G Holt (Editor). Bergey's Manual of Systematic Bacteriology. $10^{\text {th }}$ edition, vol. 2. The Williams and Wilkins Co; Baltimore.

Kasrazadeh, M. y Genigeorgis, C. 1994. Potential growth and control of Salmonella in Hispanic type soft cheese. International Journal of Food Microbiology. 22: 127-140.

Møller, K.K., Rattray, F.P. y Ardö, Y. 2013. Application of selected lactic acid bacteria and coagulant for improving the quality of low-salt Cheddar cheese: Chemical, microbiological and rheological evaluation. International Dairy Journal. 33(2): 163-174. 
Küçüköner, E. y Haque, Z.U. 2006. Physicochemical properties of low-fat and full-fat Cheddar cheeses. International Journal of Dairy Technology. 59(3): 166-170.

Lozano-Moreno, O. y Villegas-De Gante A. 2016. Valorización simbólica del Queso Crema de Chiapas, un queso tradicional mexicano con calidad de origen. PASOS. Revista de Turismo y Patrimonio Cultural. 14(2): 459-473.

Mira-de Orduña, R., Patchett, M.L., Liu S.Q. Y Pilone, J.G. 2001. Growth and arginine metabolism of the wine lactic acid bacteria Lactobacillus buchneri and Oenococcus oeni at different $\mathrm{pH}$ values and arginine concentrations. Applied and Environmental Microbiology. 67(4): 1657-1662.

Morales-Celaya, M.F., Lobato-Calleros, C., Alvarez-Ramirez, J. y Vernon-Carter, E.J. 2012. Effect of milk pasteurization and acidification method on the chemical composition and microstructure of a Mexican pasta filata cheese. LWT-Food Science and Technology. 45(2): 132-141.

NOM-111-SSA1-1994. Bienes y servicios. Método para la cuenta de mohos y levaduras en alimentos. http://www.salud.gob. $\mathrm{mx} /$ unidades/cdi/nom/111ssa14.html.

NOM-113-SSA1-1994. Bienes y servicios. Método para la cuenta de microorganismos coliformes totales en placa. http:// www.salud.gob.mx/unidades/cdi/nom/113ssa14.html.

NOM-243-SSA1-2010. Productos y servicios. Leche, fórmula láctea, producto lácteo combinado y derivados lácteos. Disposiciones y especificaciones sanitarias. Métodos de prueba. http://www.dof.gob.mx/nota_detalle.php?codigo= 5160755\&fecha=27/09/2010.

Ortiz-Balderas, M. 2006. Identificación bioquímica de bacterias ácido lácticas aisladas a partir de productos lácteos en el Estado de Hidalgo. Tesis de Licenciatura, Instituto de Ciencias Básicas e Ingeniería, Universidad Autónoma del Estado de Hidalgo. 89 pp.

Picon A., Garde, S., Ávila, M. y Nuñez, M. 2016. Microbiota dynamics and lactic acid bacteria biodiversity in raw goat milk cheeses. International Dairy Journal. 58: 14-22.

Pszczola, D.E. 2007. Meeting the acid test. Food Technology. 5: 47-59.

Ramírez-Ramírez, J.C., Rosas-Ulloa, P., Velázquez-González, M.Y., Ulloa, J.A., Arce-Romero, F. 2011. Bacterias lácticas: importancia en alimentos y sus efectos en la salud. Revista Fuente. 2(7): 1-15.

Ramos-Izquierdo, B., Bucio-Galindo, A., Bautista-Muñoz, C., Aranda-Ibáñez, E. y Izquierdo-Reyes, F. 2009. Aislamiento, identificación y caracterización de bacterias ácido lácticas para la elaboración de queso crema tropical. Universidad y Ciencia. 25(2): 159-171.
Rangel-Ortega, S.C. 2011. Identificación y caracterización de los consorcios microbianos del queso crema tropical. Tesis de maestría. Centro de Investigación en Alimentación y Desarrollo, A. C. México, 65 pp.

Romero-Castillo, P.A., Leyva-Ruelas, G., Cruz-Castillo, J.G. y Santos-Moreno, A. 2009. Evaluación de la calidad sanitaria de quesos crema tropical mexicanos de la región de Tonalá, Chiapas. Revista Mexicana de Ingeniería Química. 8: 111119.

Sameh A., Ahmed N. y El Soda, M. 2007. Evaluation of isolated starter lactic acid bacteria in Ras cheese ripening and flavour development. Food Chemistry. 104(3): 1192-1199.

Sánchez-Macías, D., Morales-de la Nuez, A., Torres, A., HernándezCastellano, L. E., Jiménez-Flores, R., Castro, N. y Argüello, A. 2013. Effects of addition of somatic cells to caprine milk on cheese quality. International Dairy Journal. 29(2): 61-67.

Terzić-Vidojević, A., Tonković, K., Leboš-Pavunc, A., Beganović, J., Strahinić, I., Kojić, M., Veljović, K., Golić, N., Kos, B., Čadež, N., Gregurek, L., Šušković, J., Raspor, P. y Topisirović, L. 2015. Evaluation of autochthonous lactic acid bacteria as starter cultures for production of white pickled and fresh soft cheeses. LWT-Food Science and Technology. 63: 298-306.

Torres-Llanez, M.J., Vallejo-Cordoba, B., Díaz-Cinco, M.E., Mazorra-Manzano, M. A. y González-Córdova, A.F. 2006. Characterization of the natural microflora of artisanal Mexican Fresco cheese. Food Control. 17(9): 683-690.

Vázquez-Velázquez, R., Salvador-Figueroa, M., Adriano-Anaya, L., De Gyves-Córdova, G. y Vázquez-Ovando, A. 2018. Use of starter culture of native lactic acid bacteria for producing an artisanal Mexican cheese safe and sensory acceptable. CyTAJournal of Food. 16(1): 460-468.

Walstra, P., Geurts, T.J, Normen, A., Jellema, A. y Van Boekel M.A.J.S. 2001. Ciencia de la leche y tecnología de los productos lácteos. Editorial Acribia S.A. España. 730 p.

Wichchukit, S. y O'Mahony, M. 2015. The 9-point hedonic scale and hedonic ranking in food science: some reappraisals and alternatives. Journal of the Science of Food and Agriculture. 95: 2167-2178.

Zheng, Y., Liu, Z. y Mo, B. 2016. Texture profile analysis of sliced cheese in relation to chemical composition and storage temperature. Journal of Chemistry. Article ID 8690380. 